\title{
Gestational Diabetes Mellitus: review of the diagnosis, clinical implications and management
}

Vincent Wing-Ming Wong 1

Director of Diabetes and Endocrine Service, Liverpool Hospital

\section{Abstract}

Gestational diabetes mellitus (GDM) is a condition that affects the wellbeing of mother and fetus. Women with GDM are at risk of type 2 diabetes mellitus in the future, while fetal exposure to hyperglycaemia in-utero may affect their glycometabolic profile later in life. Appropriate screening and management of this problem is important in ensuring good pregnancy outcomes. In this review, the clinical implications, the various ways to screen and diagnose GDM, and management strategies during pregnancy will be discussed. For years, insulin is the mainstay of treatment if medical nutrition therapy fails to maintain adequate glycaemic control, but use of other oral pharmacotherapy may gain greater acceptance in the future. Following delivery, ongoing follow-up of these women is worthwhile as early intervention through lifestyle or pharmacotherapy may prevent the development of diabetes.

\section{Keywords}

Gestational diabetes; Insulin therapy; Pregnancy outcomes 


\section{Introduction}

Gestational diabetes mellitus (GDM) is defined as glucose intolerance which is first detected during pregnancy [1]. Women with GDM are distinct from women who have pre-existing type 1 or type 2 diabetes mellitus at the time of pregnancy. The prevalence of GDM worldwide is difficult to determine, because the diagnostic criteria adopted by different countries vary greatly, and certain ethnic groups have higher risks of developing GDM [2]. In a large study in United Kingdom involving over 11,000 women, the incidence of gestational diabetes was found to be $0.4 \%$ in Caucasians, $1.5 \%$ for Africans, up to $7.3 \%$ in East Asians and $4.4 \%$ among women from South Asia [3]. In United States, the estimated prevalence was 7\%, but this may change following adoption of the new diagnostic criteria for GDM in accordance with the International Association of Diabetes and Pregnancy Study Groups (IADPSG) [1]. Apart from ethnicity, other risk factors for GDM include older age, obesity, family history of diabetes, past history of delivery of macrosomic babies and past history of GDM [4].

In this review, we will discuss the clinical relevance of GDM, the diagnostic criteria and screening strategies, management principles as well as post-partum care of women with GDM.

\section{Adverse effects of gestational diabetes}

Insulin sensitivity and secretion vary during different stages of pregnancy. In first trimester as well as early in second trimester, an increase in insulin sensitivity occurs mainly due to the relatively higher levels of estrogens. However, in the late second and early third trimesters, the increase release of hormones including human placental lactogen, leptin, prolactin, and cortisol from the placenta are responsible for the increase in insulin resistance [5]. When the woman's insulin secretory capacity cannot cope with the increase in demand, glucose intolerance develops.

Glucose is transported freely from maternal to fetal circulation, whereas maternal insulin does not cross the placental barrier [6]. In 1952, in his PhD thesis, Jorgen Pedersen postulated that maternal hyperglycemia, as seen in women with GDM, led to fetal hyperglycemia that, in turn, evoked an exaggerated fetal insulin response [7]. Macrosomia is generally defined as birth-weight in excess of 4,0004,500 g [6]. Mean blood glucose level (BGL) strongly correlated with neonatal birth-weight in women with GDM, and the degree of macrosomia was also found to be associated with fetal plasma insulin immune-reactivity and blood $\mathrm{pH}[8,9]$. Fetal pancreatic beta-cell hyperplasia is implicated in the pathogenesis of fetal acidemia and macrosomia [9]. Large fetuses are susceptible to injury such as shoulder dystocia and newborn asphyxia during vaginal birth delivery.

It was generally believed that offspring of women with GDM do not have an increased risk of congenital abnormalities, as fetal exposure of hyperglycaemia is more prominent in second and third trimester of pregnancy. However, in a meta-analysis, a higher risk of major congenital malformations was observed in infants of women with gestational diabetes with relative risk of 1.16 in cohort studies and odds ratio (OR) of 1.4 in case control studies [10]. This may be partly due to the inadvertent inclusion of some women with overt hyperglycemia or pre-existing diabetes in the analysis. However, it is also possible that in some women with GDM, mild degree of hyperglycaemia during first trimester, which is the critical period for organogenesis, is sufficient to result in fetal abnormality. Even though this risk in GDM is increased, it is still much lower than that in women with pre-existing diabetes.

A number of studies confirmed that pregnancies complicated by GDM were associated with a higher risk of adverse outcomes. The Hyperglycaemia and Adverse Pregnancy Outcome Study (HAPO) is the largest study to date involving over 25,000 women at 15 centers from 9 countries that assessed the relationship between glycaemia and obstetric outcomes [11]. The main findings of the study were that the fasting, 1-hour and 2-hour glucose levels on the 75 gram oral glucose tolerance test (OGTT) all had positive correlations with macrosomia and cord C-peptide levels above $90^{\text {th }}$ percentile [11]. 
In addition, weaker associations were found between glucose levels and need for Caesarian section as well as neonatal hypoglycaemia. These relationships persisted after adjustments of confounders including maternal age, body mass index and other clinical variables, suggesting that influence of maternal glycemia on fetal outcomes is a basic biologic phenomenon. Interestingly, the association appeared to be continuous and there is no obvious threshold at which the risks become elevated.

In a systematic review of studies looking at pregnancy outcomes, a greater risk of macrosomia $(\mathrm{OR}=1.81)$, peri-natal mortality $(\mathrm{OR}=1.55)$, pre-eclampsia $(\mathrm{OR}=1.69)$ and Caesarian Section $(\mathrm{OR}=1.37)$ was observed in women with GDM [12]. Hypoglycaemia was commonly observed in neonates whose mother had GDM, but again there was no obvious threshold at which this risk increased [11]. The neonates were also at a higher risk for jaundice, polycythaemia, respiratory distress and hypocalcemia [13]. Finally, fetuses of women with GDM are at higher risk of intrauterine demise, and this risk of fetal death in-utero is related to poor glycemic control [14].

\section{Diagnosis and screening}

Currently, there are a number of different diagnostic criteria for GDM, which makes comparison of the epidemiology and outcomes across different countries difficult (Table I).

Because there is no clear threshold glucose level above which the risk of adverse pregnancy outcome increases, it is hard to reach consensus on the diagnostic glucose cut-off levels for GDM. Most diagnostic tests use the 2-hour 75gram OGTT, but in United States, the National Diabetes Diagnostic Group (NDDG) had favored the use of the 3-hour $100 \mathrm{~g}$ OGTT. Following the HAPO Study, the IADPSG had advocated using $75 \mathrm{~g}$ OGTT, with GDM diagnosed by at least of the criteria: fasting glucose level $\leq 5.1$, 1-hour glucose level $\leq 10.0 \mathrm{mmol} / \mathrm{l}$ or 2 -hour glucose level $\leq 8.5 \mathrm{mmol} / \mathrm{l}$.

The strategies of screening for GDM during pregnancy vary between different countries, and this may be related to the prevalence of diabetes in the region and the resources available. In some countries such as Australia, universal screening is recommended [4]. In that country, women who are considered at high risk for GDM (women who are obese, belong to certain ethnic groups, have family history of diabetes or have previous history of GDM) may be recommended to undergo OGTT after the first antenatal visit in first trimester [4]. This is to exclude women who may already have pre-existing diabetes at the time of pregnancy. If found to be negative for GDM, the OGTT can be repeated between 24 and 28 weeks of gestation [15].

Performing OGTT on all pregnant women is labor intensive and takes up substantial amount of time and resources for midwives, obstetrician as well as pathology services. Furthermore, some women may not tolerate the glucose loading well, especially for those with persisting morning sickness during

\begin{tabular}{|lcccc|}
\hline & IADPSG & ADA - NDDG & ADIPS & WHO \\
\hline Glucose load for glucose tolerance test & $75 \mathrm{~g}$ & $100 \mathrm{~g}$ & $75 \mathrm{~g}$ & $75 \mathrm{~g}$ \\
Fasting glucose $(\mathrm{mmol} / \mathrm{l})$ & $\geq 5.1$ & $\geq 5.3$ & $\geq 5.5$ & $\geq 7.0$ \\
1-hour glucose level $(\mathrm{mmol} / \mathrm{l})$ & $\geq 10$ & $\geq 10.0$ & - & - \\
2-hour glucose level $(\mathrm{mmol} / \mathrm{l})$ & $\geq 8.5$ & $\geq 8.6$ & $\geq 8.0$ & $\geq 11.1$ \\
3-hour glucose level $(\mathrm{mmol} / \mathrm{l})$ & - & 2 or more & 1 or more & 1 or more \\
\hline To diagnose GDM, abnormal result in: & 1 or more & & & - \\
\hline
\end{tabular}

Table I. Different diagnostic criteria for gestational diabetes

ADA = American Diabetes Association; ADIPS = Australian Diabetes in Pregnancy Society;

IADPSG = International Association of Diabetes and Pregnancy Study Group; NDDG = National Diabetes

Diagnostic Group; WHO = World Health Organization 
pregnancy. In one study, the failure rate of OGTT can be as high as $10 \%$ (16). It was proposed that women who are low-risk (age $<25$ years, normal pre-pregnant weight, no known diabetes in first-degree relatives or member of an ethnic group with low prevalence of GDM) may not need screening, and women of average risk may be tested at 24-28 week of gestation [15]. The 1-hour 50g glucose challenge test (GCT) has also been advocated for the screening of GDM. This test is more convenient for the women as it can be done at any time of the day and does not involve overnight fasting. In some centers in Australia, this is used as a screening tool for low-risk women [4]. Women with glucose level above $7.8 \mathrm{mmol} / \mathrm{l}$ following the $50 \mathrm{~g}$ GCT will proceed to the $75 \mathrm{~g}$ OGTT. In a retrospective analysis of women who underwent $50 \mathrm{~g}$ GCT during pregnancy, at a glucose cut-off value of $11 \mathrm{mmol} / \mathrm{l}$, the positive predictive value for GDM was $85.3 \%$, based on the subsequent OGTT [17]. However, for women with GCT above $7.8 \mathrm{mmol} / \mathrm{l}$, only $45 \%$ of the women actually had GDM on the OGTT. In a systematic review, the sensitivity of the GCT was only 0.74 while the specificity was 0.77 , at the glucose cut-off level of $7.8 \mathrm{mmol} / 1$ [18]. As a result, the GCT cannot replace the $75 \mathrm{~g}$ OGTT and is gradually being phased out in many centers.

\section{Why is GDM worth treating?}

The benefits of intervention in women with GDM had been validated in a two clinical trials. In the Australian Carbohydrate Intolerance Study in Pregnant Women (ACHOIS), tight glycaemic control (maintaining fasting or pre-prandial glucose level below $5.5 \mathrm{mmol} / \mathrm{l}$ and 2-hour post-prandial glucose level below $7.0 \mathrm{mmol} / \mathrm{l}$ ) was shown to result in improved pregnancy outcomes [19]. The rate of serious peri-natal complications (including death, shoulder dystocia, bone fracture, and nerve palsy) was significantly lower among the infants of women randomized to the intervention group than that among the infants of women who received standard care [19]. Moreover, at 3 months post-partum, the women's mood and quality of life was consistently better among those who were actively treated for GDM [19]. In another study by Landon et al., for women with milder degree of hyperglycaemia, tighter glycaemic control (fasting glucose level below $5.3 \mathrm{mmol} / \mathrm{l}$ and 2-hour post-prandial glucose level below $6.7 \mathrm{mmol} / \mathrm{l}$ ) in women with GDM did not significantly lower the frequency of adverse outcomes (including stillbirth or perinatal death and other neonatal complications) [20]. However, tighter glycaemic control reduced the risks of fetal overgrowth, shoulder dystocia, cesarean delivery, and hypertensive disorders [20]. In a meta-analysis including 5 randomized clinical trials (including the 2 trials discussed), treatment for gestational diabetes through reducing glucose levels during pregnancy, lowered the risk for some peri-natal complications such as shoulder dystocia and pre-eclampsia [21].

The concern of whether the diagnosis and treatment of GDM would cause negative emotional impact on women was partly addressed in ACHOIS. Women in the intervention group, both during the antenatal period and 3-months post-partum, were found to have improved health-related quality of life, together with a reduction in the incidence of post-partum depression [19]. These findings were contrary to reports suggesting women's perception of their own health may decline with the screening process of GDM [22]. Currently there is lack of clear evidence indicating that GDM is associated with anxiety or depression $[23,24]$.

\section{Management principles and glycaemic targets}

Following diagnosis of GDM, the management of GDM requires a multi-disciplinary approach and involves diabetologists, diabetes nurse educator, dietitians as well as obstetricians and midwives. The women are usually reviewed by a diabetes nurse educator, and they are informed about the clinical implications of GDM and how this can be managed. Self blood glucose monitoring (SMBG) is initiated and the women are advised to perform SMBG in the fasting state and 1 or 2 hours post-prandial (i.e. 4 
times a day). The target BGLs during pregnancy varied in different countries, and are usually based on the 2 randomized trials mentioned above (fasting BGL $\leq 5.3$ or $5.5 \mathrm{mmol} / \mathrm{l}$, while 2-hour post-prandial $\mathrm{BGL} \leq 6.7$ or $7.0 \mathrm{mmol} / \mathrm{l})[19,20]$. The ADA guidelines set the glycaemic targets at fasting $\mathrm{BGL} \leq 5.8$ $\mathrm{mmol} / \mathrm{l}, 1$-hour BGL $\leq 8.6 \mathrm{mmol} / \mathrm{l}$ and 2 -hour BGL $\leq 7.2 \mathrm{mmol} / 1$ [15]. The need to continue SMBG as frequent as 4 times a day in women who maintain good diabetes control by 36 weeks' gestation and who do not have evidence of macrosomia on progress fetal ultrasound is uncertain.

There have been some proponents for the determination of BGL targets based on obstetric ultrasonic findings [25]. It was proposed that if there is evidence of fetal abdominal circumference exceeding $75^{\text {th }}$ percentile on ultrasound, the mother should be subjected to stricter glycaemic control. On the other hand, the glycaemic targets can be relaxed if ultrasonic examination has demonstrated normal fetal growth. In a randomized study based on this hypothesis, setting glycaemic targets according to fetal growth had been shown to be safe with similar pregnancy outcomes when compared with standard approach [25]. Inclusion of fetal growth might provide the opportunity to reduce glucose testing in low-risk pregnancies. The problem of this approach is that it does not take into account of genetic factors which are important determinants of fetal size [5]. Furthermore, most of the fetal ultrasound measurements are not corrected for the ethnicity of the parents and may have a wide error margin.

The use of glycosylated hemoglobin (HbAlc) as a glycemic goal in the management of GDM is controversial. HbAlc levels did not adequately separate women with normal pregnancy from those with GDM, and HbA1c levels decline in normal pregnancy [26]. HbA1c correlated with rates of congenital anomalies and early fetal deaths in pregnant women with pre-existing diabetes, but its role in assessing women with GDM is unclear [5,27]. Most studies found poor to low correlation between glycosylated hemoglobin and mean, fasting, pre-meal, and post-meal blood glucose values. In a study involving normal pregnancy or women with GDM, HbA1c did not correlate strongly with OGTT parameters and elevated HbA1c was not associated with macrosomia [28]. Findings from HAPO suggested that HbAlc was not a useful alternative to OGTT in pregnant women [29].

\section{Medical nutritional therapy and physical activity}

All women with GDM should receive counseling from a dietitian, and individualization of medical nutrition therapy (MNT), based on maternal weight and height, is appropriate [15]. Apart from trying to meet BGL targets, the provision of adequate calories and nutrients for pregnancy needs should be part of the dietary advice. In a randomized control study, women who were given MNT in Diabetes Clinics were shown to be less likely to require insulin therapy and had a lower HbAlc compared to women who were in the usual care group, but there was no significant difference in birth-weight [30]. In the literature, there were few studies looking at the benefits of various diets on obstetric outcomes. A diet with low glycaemic index (GI) is often recommended for women with GDM. Studies confirmed that the low GI diet is safe and well tolerated in normal pregnancies, but there has not been sufficient evidence to demonstrate benefits in pregnancy outcomes in GDM. In a study involving pregnant women without GDM, those on a low GI diet from second trimester onwards gave birth to infants with lower birth-weight, lower ponderal index and lower prevalence of large-for gestational age [31]. On the other hand, in a small study involving woman with GDM, those randomized to low GI diet had a significantly lower rate of need for insulin therapy [32]. However, the low GI diet did not result in a significantly lower fetal birth-weight percentile or ponderal index. The restriction of carbohydrates to $35-40 \%$ of daily calorie intake was found to reduce maternal BGL and improves maternal and fetal outcomes [33].

Women with GDM are advised to start or continue moderate physical exercise during pregnancy, although the impact of exercise on neonatal complications awaits rigorous clinical trials [15]. Again, there were not many studies validating the effectiveness of exercise on pregnancy outcomes for women 
with GDM. There was a small randomized study that showed low level exercise (20 minutes three times a week for 6 weeks) for women with GDM resulted in lower fasting glucose levels, lower glucose responses to a glucose challenge, and lower HbAlc levels [34]. Another similar study demonstrated that circuit type exercise three times a week for women with GDM led to lower postprandial glucose levels, and delay in the requirement of insulin in those with BMI above 25 [35].

The Institute of Medicine (IOM) has issued some recommendations on weight gain during pregnancy [36]. The general principle is that women who are overweight prior to pregnancy should put on smaller amount of weight, and underweight women can have greater weight gain during pregnancy [36]. The IOM suggested that underweight women can put on up to 40 pounds, while in obese women, they should gain no more than 20 pounds during the entire pregnancy. However, it is not clear if the IOM recommendations are appropriate for women with GDM and there is currently no guideline regarding the optimal weight gain for women with diabetes or GDM.

\section{Insulin therapy}

When dietary and lifestyle intervention fail to maintain glucose levels within the specified targets as discussed above (upper targets for fasting BGL 5.3-5.8 mmol/1; upper targets for 2-hour post-prandial BGL 6.7-7.2 mmol/l), insulin is the pharmacologic therapy of choice [15]. Insulin does not cross the placental barrier, and has consistently been shown to reduce fetal morbidities when added to MNT [15]. The women are usually started on a small dose, and SMBG is essential to guide the titration of the insulin doses.

The proportion of women with GDM requiring insulin therapy varied between different studies, ranging between $20 \%$ and 50\% [19,37]. Factors that predict requirement of insulin therapy included elevated BMI, high fasting glucose level on OGTT, and history of previous GDM [37]. Offspring of women on insulin therapy had higher birth weight and birth-weight percentile than those of women on MNT, but there was no difference in neonatal morbidity including APGAR scores or need for neonatal intensive care support [37]. The need for insulin therapy also varied between different ethnic groups. In a cohort of over 800 women, women from south-east Asian background were least likely to need insulin therapy (37.2\%), while women from Pacific Islands had the highest (65.6\%) [38].

The choice of the type of insulin will depend on the woman's glycaemic profile. For women with elevated fasting BGL, night-time basal insulin (intermediate-acting insulin such as Isophane insulin) is usually initiated. For women whose post-prandial BGLs are elevated, regular insulin (short-acting) is appropriate. The combination of night-time basal insulin and meal time short-acting insulin is referred to basal-bolus regimen. In addition to basal-bolus regimen, twice daily pre-mixed insulin (combination of short and intermediate-acting insulin) is sometimes used. A study comparing basal-bolus regimen with pre-mixed insulin demonstrated that basal-bolus insulin regimen resulted in a lower rate of overall neonatal morbidity than the twice daily pre-mixed insulin regimen, and the relative risk for hyper-bilirubinaemia and hypoglycaemia was lower [39].

Human insulin is safe to be used during pregnancy, but in the last 10 years, there has been more widespread use of rapid-acting insulin analogues such as Insulin Lispro and Insulin Aspart. Studies had shown that these rapid-acting insulin analogues are safe to be used in pregnancy with no evidence of increase adverse pregnancy outcomes [40-43]. On the other hand, the safety profiles of the more long-acting insulin analogues such as Insulin Glargine and Insulin Detemir have not been fully validated for use in pregnancy. Emerging evidence suggests that the use of these long-acting analogues does not result in adverse maternal or fetal outcomes [44-46]. For women with pre-existing type 1 diabetes, it may be appropriate to continue these basal insulin analogues during pregnancy, since changing insulin therapy during pregnancy can result in a period of glycometabolic instability. These long-acting insulin analogues may also be considered if the woman develops an allergic reaction to Isophane insulin. 


\section{Oral anti-hyperglycaemic agents}

Oral anti-hyperglycaemic agents (AHG) are usually not recommended for use during pregnancy because of the potential risks of neonatal hypoglycemia and teratogenicity associated with placental transfer of the drug to the fetus [47]. However, the use of a few oral AHG has received considerable attention following a number of clinical studies. In South Africa, metformin had been used for over 30 years, but its safety and effectiveness was not formally assessed [48,49]. In the Metformin In Gestational Diabetes (MiG) trial where 751 women with GDM who failed MNT were randomized to either insulin therapy or metformin, the use of metformin in late $2^{\text {nd }}$ and $3^{\text {rd }}$ trimester in women with GDM was not associated with increased peri-natal complications as compared with insulin therapy [50]. In addition, more women in the metformin group preferred their assigned therapy compared to those in the insulin group. As part of this trial, in a small number of women where cord blood was assessed, it is important to note that placental transfer of metformin is considerable, and the fetal level of metformin is about half that of the maternal level [51]. In the follow-up study of MiG, up to the age of 2 years, children who were exposed to metformin in-utero had larger measures of subcutaneous fat, but overall body fat was the same as in children whose mothers were treated with insulin alone [52]. The findings of MiG are promising but we should await longer term follow up of the offspring of women in the metformin group.

In United States, there is emerging interest for the use of sulphonylureas, especially glyburide, during pregnancy. In a randomized study comparing glyburide with insulin therapy, women treated with glyburide achieved similar degree of glycaemic control to those in the insulin group [53]. The risks of macrosomia, respiratory distress, neonatal hypoglycaemia and need for neonatal intensive care support were not different between the 2 groups. Compared to metformin, placental transfer of glyburide was minimal [54]. Currently neither metformin or glyburide is endorsed by Food and Drug Authority for use during pregnancy [15].

In a meta-analyses of studies including over 1,300 women with GDM, treatment with oral AHG (essentially the 2 medications: glyburide and metformin) achieved comparable glycaemic levels as those on insulin therapy, and use of AHG was not associated with increased peri-natal complications or macrosomia $[47,55]$. Nevertheless, the total number of women included in these studies was still quite small, and long term effects on the off-spring were not available. At the moment, due to lack of clinical studies, AHGs such as acarbose, thiazolidinediones, dipeptidyl-peptidase 4 inhibitor and glucagon-like peptide 1 analogues should not be used during pregnancy. More safety data will be required before these agents can become part of routine management of diabetes during pregnancy.

\section{Obstetrics management and delivery}

There has been a lack of clinical studies that evaluate the optimal obstetric management of women with GDM. The consensus is that all women with GDM should monitor fetal movement during the last 8-10 weeks of pregnancy and any reduction in the perception of fetal movement should be reported immediately [56]. The use of fetal imaging using ultrasound is often performed in third trimester to detect any accelerated fetal growth. This may be particularly important in women with poor glycaemic control or women who are on insulin therapy. There is certainly a need to refine fetal and pelvic imaging techniques to help identify maternal-fetal pairs for Caesarian section to avoid complications such as shoulder dystocia [56]. The main dilemma revolves balancing the maternal and fetal risks: the chance of damage to the mother with GDM from cesarean delivery versus the chance of adverse impact on the fetus from events such as shoulder dystocia at vaginal delivery [56].

In the area of optimal timing and mode of delivery to avoid fetal injury, large well-controlled prospective studies do not currently exist [56]. In a systematic review on the delivery management of women 
with GDM, one randomized control study demonstrated that active induction at term resulted in lower rate of macrosomia than expectant labour management [57]. However, the risks of other outcomes such as shoulder dystocia, neonatal hypoglycemia, or perinatal deaths were not different. Due to the lack of well designed studies, there is little data to recommend the optimal timing and mode of delivery in order to minimize the risk of fetal injury. Having GDM alone is not sufficient indication for Caesarean section or for delivery prior to $38^{\text {th }}$ weeks of gestation [15]. Continuation of pregnancy for women with uncomplicated GDM up to 10 days past the term date may be acceptable provided that fetal wellbeing is ensured through careful monitoring [4].

Maintaining good glycaemic control during labor is important to reduce the risk of fetal acidosis and neonatal hypoglycemia [58]. The risk of other adverse neonatal metabolic outcomes (such as hyperbilirubinemia or hypocalcemia) is also related to both ante-partum and intra-partum maternal hyperglycemia and appears to increase with the degree of maternal hyperglycemia. The American College of Obstetricians and Gynecologist and the American College of Endocrinology recommended a glucose target of between 3.9 and $6.1 \mathrm{mmol} / \mathrm{l}$ during the intra-partum period $[59,60]$. During labor, especially for women who are on insulin therapy, it is common to replace subcutaneous insulin injections with intravenous insulin infusion (with or without glucose infusion at the same time), which allows fine adjustment of insulin rates to maintain strict glycaemic control. For women who have well controlled GDM on MNT alone, insulin infusion is usually not required.

\section{Post-partum care}

Following parturitions, especially after the delivery of the placenta, the hyperglycaemic effects from placental hormones dissipate rapidly, and the glycometabolic profile of women with GDM returns to their pre-pregnancy state almost immediately. However, some women with GDM actually have undiagnosed type 2 diabetes mellitus, and hence it is prudent to monitor the women's BGL up to 48 hours post-partum. It is important that women with GDM are made aware of their increased risk of recurrent GDM in their subsequent pregnancies as well as their increased risk of developing type 2 diabetes in the future. Predictors of the development of type 2 diabetes included elevated maternal BMI, need for insulin therapy during pregnancy, and glucose level during OGTT at the time of diagnosis of GDM [61]. The rates of development of type 2 diabetes are much higher in several non-European ethnic groups. The prevalence of type 2 diabetes in Polynesian women was reported to be $30 \%$, while for Latino women, they have a $47 \%$ cumulative incidence of type 2 diabetes 5 years after delivery [4,62]. It is therefore important that these women should have a repeat OGTT, probably about 6-12 weeks post-partum. The OGTT should be repeated every 2 years thereafter to allow early detection of type 2 diabetes [4]. The development of cardiovascular disease was found to be higher in women with GDM and this occurred at a younger age, independent of the metabolic syndrome and type 2 diabetes [63] . It is therefore important to also address the various reversible cardiovascular risk factors such as smoking, obesity, hypertension, and hyperlipidemia, and this should be part of the post-partum care for this group of women.

Because women with GDM have such high risk of developing type 2 diabetes mellitus later in life, this group of patients may provide a unique opportunity to study the early pathogenesis of diabetes. They represent a high risk group where intervention may be worthwhile in preventing the development of diabetes or vascular disease. As part of a sub-analysis of the Diabetes Prevention Program, women with a history of GDM had a substantially higher risk of developing diabetes later in life compared to parous women without GDM [64]. For women who had GDM in the past, both intensive lifestyle and metformin therapy reduced the incidence of diabetes by approximately $50 \%$ compared with the placebo group, whereas this reduction was 49 and 14\%, respectively in women whose previous pregnancies were not 
complicated by GDM. However, routine use of metformin in women with a history of GDM to prevent diabetes is not justified. The Troglitazone in Prevention of Diabetes (TRIPOD) study was conducted on Hispanic women with recent GDM, and those who were randomized to treatment with the insulinsensitizing drug troglitazone for a median duration of 30 months had a 55\% reduction in the incidence of type 2 diabetes [65]. Protection from diabetes was closely linked to initial reductions in endogenous insulin requirements and ultimately associated with stabilization of pancreatic cell function [65].

As for the offspring of women with GDM, infants of women with gestational diabetes have increased body fat compared with weight-matched infants of control women [66]. The birth weight of these infants normalized by one year, but the weight increased again during early childhood. The offspring of mothers with GDM and who were born large for gestational age were at significant risk of developing metabolic syndrome in childhood [67]. The intra-uterine exposure to hyperglycaemia may have important glycometabolic implications for the offspring later in their life. In a study looking at parental history of diabetes, GDM was twice as common in the daughters of mothers with diabetes (11\%) than fathers with diabetes (5\%) [68]. The excess of maternal transmission of diabetes implies an epigenetic effect of in-utero hyperglycaemia acting in addition to genetic factors to produce diabetes in the next generation. More research is needed to assess the level of glycaemic control during pregnancy on the glycol-metabolic state of offspring when they reach adulthood.

\section{Conclusion}

The rise in the incidence of GDM mirrors that of type 2 diabetes in many countries, and it is draining a significant amount of resources for diabetes services world-wide. Optimal management of women with GDM is important in ensuring good pregnancy outcomes. Risk stratification may be invaluable, as this may allow greater resources to be directed to women at higher risk, and avoidance of over-treatment of women at low risk. To be able to achieve this, there is a need for a multi-disciplinary team approach that includes diabetologists, diabetes nurse educators, dietitians, midwives and obstetricians. Good communication between these clinicians (in relaying information including maternal glycometabolic state and fetal biophysical profile) is essential in assessing the risk profile of the pregnancy and in determining the most favorable timing and method of delivery of women with GDM. Ongoing research will be needed in assessing the safety profiles of the newer AHG as well as basal insulin analogues during pregnancy, and consensus is required in determining the optimal obstetric management of women with GDM. Finally, greater effort should be made in devising best strategy to prevent the development of type 2 diabetes in these women as well as their offspring.

Question for further research

- Areas that need further research include:

- To determine the most appropriate medical nutrition therapy for women with GDM, and the effects and safety of different diets on pregnancy outcomes

- The safety profile of various oral anti-hyperglycaemic medications as well as the long-acting insulin analogues to be used during pregnancy

- Strategies in the obstetric management of women with GDM including timing and frequency of ultrasound and timing of delivery

- Intra-partum management of women with GDM

- Long term follow-up of women with GDM: strategies to reduce their risk cardiovascular disease

- To assess the relationship between level of glycaemic control during pregnancy and the glycometabolic profile of offspring of women with GDM 


\section{The review in brief}

Clinical question This review summarized the clinical problem of GDM in terms of its pathogenesis, diagnosis, the management strategies including medical nutritional therapy, insulin therapy as well as the potential use of oral anti-hyperglycaemic medications (AHG). The obstetric management for women with GDM was discussed briefly, and the long term implications of GDM on the mother and the child will also be outlined

Type of review Narrative

Search of the PubMed with keywords: gestational diabetes mellitus, diagnosis, pregnancy outcomes, management, literature medical nutritional therapy, insulin therapy, oral anti-hyperglycaemic medication, cardiovascular disease

Conclusion For years, the diagnosis of GDM differs greatly between various countries, but the new criteria based on the HAPO study as recommended by IADPSG is likely to be adopted more widely worldwide. Management of GDM involves multi-disciplinary approach and includes medical nutritional therapy and insulin therapy, but available data for use of oral AHG during pregnancy is promising. Careful obstetric monitoring for these women is important, and maintaining good glycaemic control throughout pregnancy is shown to be beneficial in pregnancy outcomes. Ongoing follow-up of women with GDM post-partum is worthwhile, as they are at a very high risk of developing metabolic syndrome or type 2 diabetes later in their lives.

\section{Reference}

1. Diagnosis and classification of diabetes mellitus. Diabetes Care 2012; 35 Suppl 1: S64-71; http:// dx.doi.org/10.2337/dc12-s064

2. Anna V, van der Ploeg HP, Cheung NW, et al. Sociodemographic correlates of the increasing trend in prevalence of gestational diabetes mellitus in a large population of women between 1995 and 2005. Diabetes Care 2008; 31: 2288-93; http://dx.doi.org/10.2337/dc08-1038

3. Dornhorst A, Paterson CM, Nicholls JS, et al. High prevalence of gestational diabetes in women from ethnic minority groups. Diabet Med 1992; 9: 820-5; http://dx.doi.org/10.1111/j.1464-5491.1992. tb01900.x

4. Hoffman L, Nolan C, Wilson JD, et al. Gestational diabetes mellitus--management guidelines. The Australasian Diabetes in Pregnancy Society. Med J Aust 1998; 169: 93-7

5. Hod M, Yogev Y. Goals of metabolic management of gestational diabetes: is it all about the sugar? Diabetes Care 2007; 30 Suppl 2: S180-7; http://dx.doi.org/10.2337/dc07-s213

6. Reece EA, Leguizamon G, Wiznitzer A. Gestational diabetes: the need for a common ground. Lancet 2009; 373: 1789-97; http://dx.doi.org/10.1016/S0140-6736(09)60515-8

7. Pedersen J. Diabetes and pregnancy: blood sugar of newborn infants [PhD thesis]. Copenhagen: Danish Science Press, 1952: 230

8. Langer O, Levy J, Brustman L, et al. Glycemic control in gestational diabetes mellitus--how tight is tight enough: small for gestational age versus large for gestational age? Am J Obstet Gynecol 1989; 161: 646-53

9. Salvesen DR, Brudenell JM, Proudler AJ, et al. Fetal pancreatic beta-cell function in pregnancies complicated by maternal diabetes mellitus: relationship to fetal acidemia and macrosomia. Am J Obstet Gynecol 1993; 168: 1363-9

10. Balsells M, Garcia-Patterson A, Gich I, et al. Major congenital malformations in women with gestational diabetes mellitus: a systematic review and meta-analysis. Diabetes Metab Res Rev 2012; 28: 252-7; http://dx.doi.org/10.1002/dmrr.1304

11. Metzger BE, Lowe LP, Dyer AR, et al. Hyperglycemia and adverse pregnancy outcomes. $N$ Engl J Med 2008; 358: 1991-2002; http://dx.doi.org/10.1056/NEJMoa0707943 
12. Wendland EM, Torloni MR, Falavigna M, et al. Gestational diabetes and pregnancy outcomes - a systematic review of the World Health Organization (WHO) and the International Association of Diabetes in Pregnancy Study Groups (IADPSG) diagnostic criteria. BMC Pregnancy Childbirth 2012; 12: 23; http://dx.doi.org/10.1186/1471-2393-12-23

13. Cheung NW. The management of gestational diabetes. Vasc Health Risk Manag 2009; 5: 153-64; http://dx.doi.org/10.2147/VHRM.S3405

14. Girz BA, Divon MY, Merkatz IR. Sudden fetal death in women with well-controlled, intensively monitored gestational diabetes. J Perinatol 1992; 12: 229-33

15. ADA. Position Statement: Gestational Diabetes Mellitus. Diabetes Care 2004; 27(Supp1): S88-90; http://dx.doi.org/10.2337/diacare.27.2007.S88

16. Agarwal MM, Hughes PF, Punnose J, et al. Fasting plasma glucose as a screening test for gestational diabetes in a multi-ethnic, high-risk population. Diabet Med 2000; 17: 720-6; http://dx.doi. org/10.1046/j.1464-5491.2000.00371.x

17. Wong VW, Garden F, Jalaludin B. Hyperglycaemia following glucose challenge test during pregnancy: when can a screening test become diagnostic? Diabetes Res Clin Pract 2009; 83: 394-6; http://dx.doi.org/10.1016/j.diabres.2008.11.026

18. van Leeuwen $\mathrm{M}$, Louwerse MD, Opmeer BC, et al. Glucose challenge test for detecting gestational diabetes mellitus: a systematic review. BJOG 2012; 119: 393-401; http://dx.doi.org/10.1111/j.14710528.2011.03254.x

19. Crowther CA, Hiller JE, Moss JR, et al. Effect of treatment of gestational diabetes mellitus on pregnancy outcomes. N Engl J Med 2005; 352: 2477-86; http://dx.doi.org/10.1056/NEJMoa042973

20. Landon MB, Spong CY, Thom E, et al. A multicenter, randomized trial of treatment for mild gestational diabetes. N Engl J Med 2009; 361: 1339-48; http://dx.doi.org/10.1056/NEJMoa0902430

21. Horvath $\mathrm{K}$, Koch $\mathrm{K}$, Jeitler K, et al. Effects of treatment in women with gestational diabetes mellitus: systematic review and meta-analysis. BMJ 2010; 340: c1395; http://dx.doi.org/10.1136/bmj. c1395

22. Kerbel D, Glazier R, Holzapfel S, et al. Adverse effects of screening for gestational diabetes: a prospective cohort study in Toronto, Canada. J Med Screen 1997; 4: 128-32

23. Katon JG, Russo J, Gavin AR, et al. Diabetes and depression in pregnancy: is there an association? J Womens Health (Larchmt) 2011; 20: 983-9; http://dx.doi.org/10.1089/jwh.2010.2662

24. Byrn MA, Penckofer S. Antenatal depression and gestational diabetes: A Review of Maternal and Fetal Outcomes. Nurs Womens Health 2013; 17: 22-33; http://dx.doi.org/10.1111/1751-486X.12003

25. Schaefer-Graf UM, Kjos SL, Fauzan OH, et al. A randomized trial evaluating a predominantly fetal growth-based strategy to guide management of gestational diabetes in Caucasian women. Diabetes Care 2004; 27: 297-302; http://dx.doi.org/10.2337/diacare.27.2.297

26. Kurishita M, Nakashima K, Kozu H. Glycated hemoglobin of fractionated erythrocytes, glycated albumin, and plasma fructosamine during pregnancy. Am J Obstet Gynecol 1992; 167: 1372-8

27. Inkster ME, Fahey TP, Donnan PT, et al. The role of modifiable pre-pregnancy risk factors in preventing adverse fetal outcomes among women with type 1 and type 2 diabetes. Acta Obstet Gynecol Scand 2009; 88: 1153-7; http://dx.doi.org/10.1080/00016340903176859

28. Cocilovo G, Guerra S, Colla F, et al. Glycosylated hemoglobin (HbA1) assay as a test for detection and surveillance of gestational diabetes. A reappraisal. Diabete Metab 1987; 13: 426-30

29. Lowe LP, Metzger BE, Dyer AR, et al. Hyperglycemia and Adverse Pregnancy Outcome (HAPO) Study: associations of maternal A1C and glucose with pregnancy outcomes. Diabetes Care 2012; 35: 574-80; http://dx.doi.org/10.2337/dc11-1687

30. Reader D, Splett P, Gunderson EP. Impact of gestational diabetes mellitus nutrition practice guidelines implemented by registered dietitians on pregnancy outcomes. J Am Diet Assoc 2006; 106: 1426-33; http://dx.doi.org/10.1016/j.jada.2006.06.009 
31. Moses RG, Luebcke M, Davis WS, et al. Effect of a low-glycemic-index diet during pregnancy on obstetric outcomes. Am J Clin Nutr 2006; 84: 807-12

32. Moses RG, Barker M, Winter M, et al. Can a low-glycemic index diet reduce the need for insulin in gestational diabetes mellitus? A randomized trial. Diabetes Care 2009; 32: 996-1000; http://dx.doi. org/10.2337/dc09-0007

33. Major CA, Henry MJ, De Veciana M, et al. The effects of carbohydrate restriction in patients with diet-controlled gestational diabetes. Obstet Gynecol 1998; 91: 600-4; http://dx.doi.org/10.1016/ S0029-7844(98)00003-9

34. Jovanovic-Peterson L, Durak EP, Peterson CM. Randomized trial of diet versus diet plus cardiovascular conditioning on glucose levels in gestational diabetes. Am J Obstet Gynecol 1989; 161: 415-9

35. Brankston GN, Mitchell BF, Ryan EA, et al. Resistance exercise decreases the need for insulin in overweight women with gestational diabetes mellitus. Am J Obstet Gynecol 2004; 190: 188-93; http://dx.doi.org/10.1016/S0002-9378(03)00951-7

36. Institute Of Medicine. Weight gain during pregnancy: reexamining the guidelines. National Academy Press. 2009

37. Wong VW, Jalaludin B. Gestational diabetes mellitus: who requires insulin therapy? Aust $N Z J$ Obstet Gynaecol 2011; 51: 432-6; http://dx.doi.org/10.1111/j.1479-828X.2011.01329.x

38. Wong VW. Gestational diabetes mellitus in five ethnic groups: a comparison of their clinical characteristics. Diabet Med 2012; 29: 366-71; http://dx.doi.org/10.1111/j.1464-5491.2011.03439.x

39. Nachum Z, Ben-Shlomo I, Weiner E, et al. Twice daily versus four times daily insulin dose regimens for diabetes in pregnancy: randomised controlled trial. BMJ 1999; 319: 1223-7; http://dx.doi. org/10.1136/bmj.319.7219.1223

40. Aydin Y, Berker D, Direktor N, et al. Is insulin lispro safe in pregnant women: Does it cause any adverse outcomes on infants or mothers? Diabetes Res Clin Pract 2008; 80: 444-8; http://dx.doi. org/10.1016/j.diabres.2008.02.004

41. Hod M, Damm P, Kaaja R, et al. Fetal and perinatal outcomes in type 1 diabetes pregnancy: a randomized study comparing insulin aspart with human insulin in 322 subjects. Am J Obstet Gynecol 2008; 198: 186 e1-7

42. Pettitt DJ, Ospina P, Howard C, et al. Efficacy, safety and lack of immunogenicity of insulin aspart compared with regular human insulin for women with gestational diabetes mellitus. Diabet Med 2007; 24: 1129-35; http://dx.doi.org/10.1111/j.1464-5491.2007.02247.x

43. Wyatt JW, Frias JL, Hoyme HE, et al. Congenital anomaly rate in offspring of mothers with diabetes treated with insulin lispro during pregnancy. Diabet Med 2005; 22: 803-7; http://dx.doi. org/10.1111/j.1464-5491.2004.01498.x

44. Callesen NF, Damm J, Mathiesen JM, et al. Treatment with the long-acting insulin analogues detemir or glargine during pregnancy in women with type 1 diabetes: comparison of glycaemic control and pregnancy outcome. J Matern Fetal Neonatal Med 2013; 26: 588-92; http://dx.doi.org/10.3109 /14767058.2012.743523

45. Lepercq J, Lin J, Hall GC, et al. Meta-Analysis of Maternal and Neonatal Outcomes Associated with the Use of Insulin Glargine versus NPH Insulin during Pregnancy. Obstet Gynecol Int 2012; 2012: 649070; http://dx.doi.org/10.1155/2012/649070

46. Mathiesen ER, Hod M, Ivanisevic M, et al. Maternal efficacy and safety outcomes in a randomized, controlled trial comparing insulin detemir with $\mathrm{NPH}$ insulin in 310 pregnant women with type 1 diabetes. Diabetes Care 2012; 35: 2012-7;

47. Dhulkotia JS, Ola B, Fraser R, et al. Oral hypoglycemic agents vs insulin in management of gestational diabetes: a systematic review and metaanalysis. Am J Obstet Gynecol 2010; 203: 457 e1-9; http://dx.doi.org/10.1016/j.ajog.2010.06.044

48. Coetzee EJ, Jackson WP. Metformin in management of pregnant insulin-independent diabetics. Diabetologia 1979; 16: 241-5; http://dx.doi.org/10.1007/BF01221950 
49. Coetzee EJ, Jackson WP. Pregnancy in established non-insulin-dependent diabetics. A five-and-ahalf year study at Groote Schuur Hospital. S Afr Med J 1980; 58: 795-802

50. Rowan JA, Hague WM, Gao W, et al. Metformin versus insulin for the treatment of gestational diabetes. N Engl J Med 2008; 358: 2003-15; http://dx.doi.org/10.1056/NEJMoa0707193

51. Hague WM, Davoren PM, McIntyre D, et al. Metformin crosses the placenta: a modulator for fetal insulin resistance? BMJ 2003; 327: 880-1

52. Rowan JA, Rush EC, Obolonkin V, et al. Metformin in gestational diabetes: the offspring follow-up (MiG TOFU): body composition at 2 years of age. Diabetes Care 2011; 34: 2279-84; http://dx.doi. org/10.2337/dc11-0660

53. Langer O, Conway DL, Berkus MD, et al. A comparison of glyburide and insulin in women with gestational diabetes mellitus. N Engl J Med 2000; 343: 1134-8; http://dx.doi.org/10.1056/ NEJM200010193431601

54. Elliott BD, Langer O, Schenker S, et al. Insignificant transfer of glyburide occurs across the human placenta. Am J Obstet Gynecol 1991; 165: 807-12

55. Nicholson W, Bolen S, Witkop CT, et al. Benefits and risks of oral diabetes agents compared with insulin in women with gestational diabetes: a systematic review. Obstet Gynecol 2009; 113: 193-205

56. Conway DL. Obstetric management in gestational diabetes. Diabetes Care 2007; 30 Suppl 2: S1759; http://dx.doi.org/10.2337/dc07-s212

57. Witkop CT, Neale D, Wilson LM, et al. Active compared with expectant delivery management in women with gestational diabetes: a systematic review. Obstet Gynecol 2009; 113: 206-17

58. Curet LB, Izquierdo LA, Gilson GJ, et al. Relative effects of antepartum and intrapartum maternal blood glucose levels on incidence of neonatal hypoglycemia. J Perinatol 1997; 17: 113-5

59. ACOG Committee on Practice Bulletins. ACOG Practice Bulletin. Clinical Management Guidelines for Obstetrician-Gynecologists. Number 60, March 2005. Obstet Gynecol 2005; 105: 675-85

60. Garber AJ, Moghissi ES, Bransome ED, Jr., et al. American College of Endocrinology position statement on inpatient diabetes and metabolic control. Endocr Pract 2004; 10 Suppl 2: 4-9

61. Dalfra MG, Lapolla A, Masin M, et al. Antepartum and early postpartum predictors of type 2 diabetes development in women with gestational diabetes mellitus. Diabetes Metab 2001; 27: 675-80

62. Kjos SL, Peters RK, Xiang A, et al. Predicting future diabetes in Latino women with gestational diabetes. Utility of early postpartum glucose tolerance testing. Diabetes 1995; 44: 586-91; http:// dx.doi.org/10.2337/diabetes.44.5.586

63. Carr DB, Utzschneider KM, Hull RL, et al. Gestational diabetes mellitus increases the risk of cardiovascular disease in women with a family history of type 2 diabetes. Diabetes Care 2006; 29: 2078-83; http://dx.doi.org/10.2337/dc05-2482

64. Ratner RE, Christophi CA, Metzger BE, et al. Prevention of diabetes in women with a history of gestational diabetes: effects of metformin and lifestyle interventions. J Clin Endocrinol Metab 2008; 93: 4774-9; http://dx.doi.org/10.1210/jc.2008-0772

65. Buchanan TA, Xiang AH, Peters RK, et al. Preservation of pancreatic beta-cell function and prevention of type 2 diabetes by pharmacological treatment of insulin resistance in high-risk hispanic women. Diabetes 2002; 51: 2796-803; http://dx.doi.org/10.2337/diabetes.51.9.2796

66. Catalano PM, Kirwan JP, Haugel-de Mouzon S, et al. Gestational diabetes and insulin resistance: role in short- and long-term implications for mother and fetus. J Nutr 2003; 133(5 Suppl 2): 1674S-83S

67. Boney CM, Verma A, Tucker R, et al. Metabolic syndrome in childhood: association with birth weight, maternal obesity, and gestational diabetes mellitus. Pediatrics 2005; 115: e290-6

68. McLean M, Chipps D, Cheung NW. Mother to child transmission of diabetes mellitus: does gestational diabetes program Type 2 diabetes in the next generation? Diabet Med 2006; 23: 1213-5; http://dx.doi.org/10.1111/j.1464-5491.2006.01979.x 